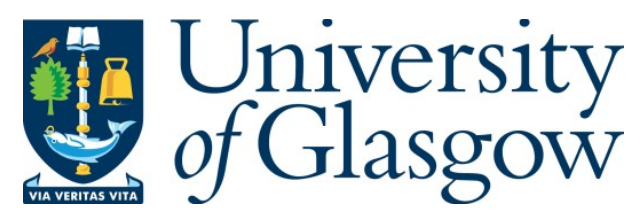

Roscoe, R. B., Elliott, C., Zarros, A., and Baillie, G. S. (2016) Non-genetic therapeutic approaches to Canavan disease. Journal of the Neurological Sciences, 366, pp. 116-124.

There may be differences between this version and the published version. You are advised to consult the publisher's version if you wish to cite from it.

http://eprints.gla.ac.uk/122560/

Deposited on: 04 October 2016

Enlighten - Research publications by members of the University of Glasgow http://eprints.gla.ac.uk 


\title{
Non-genetic therapeutic approaches to Canavan disease
}

\author{
Rebecca B. Roscoe ${ }^{1}$, Christina Elliott ${ }^{1,2}$, Apostolos Zarros ${ }^{1,3, *}$, George S. Baillie ${ }^{1}$ \\ ${ }^{1}$ Gardiner Laboratory, Institute of Cardiovascular and Medical Sciences, College of Medical, \\ Veterinary and Life Sciences, University of Glasgow, Glasgow, Scotland, UK; ${ }^{2}$ Institute of \\ Psychiatry, Psychology \& Neuroscience, King's College London, London, England, UK; \\ ${ }^{3}$ Research Department of Pharmaceutics, UCL School of Pharmacy, London, England, UK
}

Keywords: Canavan disease, $\mathrm{N}$-acetylaspartate, NAA, $\mathrm{N}$-acetylaspartylglutamate, NAAG, aspartoacylase, ASPA, oligodendrocytes, calcium acetate, ethanol, glyceryl triacetate, lithium chloride, lithium citrate, lipoic acid, pyrazole, sodium valproate, topiramate, triheptanoin

\section{*Author for correspondence:}

Dr Apostolos Zarros, physician, MRes, PhD, AMRSB, FRNS, LIBMS, MAPS, MIKE Box 318, 111 West George str., G2 1QX, Glasgow, Scotland, United Kingdom Tel.: +44-(0)141-3306388 (lab); Fax: +44-(0)141-3304620

E-mail: a.zarros.1@research.gla.ac.uk; azarros@outlook.com 


\section{ABSTRACT:}

Canavan disease (CD) is a rare leukodystrophy characterized by diffuse spongiform white matter degeneration, dysmyelination and intramyelinic oedema with consequent impairment of psychomotor development and early death. The molecular cause of CD has been identified as being mutations of the gene encoding the enzyme aspartoacylase (ASPA) leading to its functional deficiency. The physiological role of ASPA is to hydrolyse $N$-acetyl-L-aspartic acid (NAA), producing L-aspartic acid and acetate; as a result, its deficiency leads to abnormally high central nervous system NAA levels. The aim of this article is to review what is currently known regarding the aetiopathogenesis of $\mathrm{CD}$ with emphasis on the non-genetic therapeutic strategies, both at an experimental and a clinical level, by highlighting: (a) major related hypotheses, (b) the results of the available experimental simulatory approaches, as well as (c) the relevance of the so far examined markers of CD neuropathology. The potential and the limitations of the current non-genetic neuroprotective approaches to the treatment of CD are particularly discussed in the current article, in a context that could be used to direct future experimental and (eventually) clinical work in the field.

List of abbreviations: Ac: acetate; Acetyl-CoA: acetyl-coenzyme A; ACS: acetylcoenzyme A synthetase; Asp: L-aspartic acid; ASPA: aspartoacylase; AspNAT: aspartate $N$-acetyltransferase; BBB: blood-brain barrier; CA: calcium acetate; CD: Canavan disease; CNS: central nervous system; CoA: coenzyme A; ECF: extracellular fluid; Gln: glutamine; Glu: glutamate; GMR3: metabotropic glutamate receptor 3 (mGluR3); GTA: glyceryl triacetate; HPLC: high-performance liquid chromatography; 
Li: lithium; LiCl: lithium chloride; $\mathrm{Li}_{3} \mathrm{C}_{6} \mathrm{H}_{5} \mathrm{O}_{7}$ : lithium citrate; MRI: magnetic resonance imaging; MRS: magnetic resonance spectroscopy; NAA: $N$-acetyl-L-aspartic acid or $N$-acetylaspartate; NAAG: $N$-acetylaspartylglutamic acid; NPCs: neural progenitor cells; TCA: tricarboxylic acid. 


\section{Introduction}

Canavan disease (CD) is a rare leukodystrophy characterized by diffuse spongiform white matter degeneration, dysmyelination and intramyelinic oedema with consequent impairment of psychomotor development and early death (Hoshino and Kubota, 2014; Kumar et al., 2006; Matalon and Michals-Matalon, 1999a). Globus and Strauss (1928) were the first to recognise the spongy deteriorative effects of the disease, although the first clinical description was provided by Myrtelle Canavan (Canavan, 1931). Almost two decades later, Van Bogaert and Bertrand (1949) reported its autosomal recessive nature and increased prevalence amongst Ashkenazi Jewish population; notably, CD is also known as the "Canavan-Van Bogaert-Bertrand" disease. The molecular cause of CD was identified many years later (Matalon et al., 1988) as the presence of mutations within the gene encoding the enzyme aspartoacylase (ASPA; EC 3.5.1.15; N-acetyl-Laspartate amidohydrolase) located on the short arm of chromosome 17 (17p13.3). However, since the purification and characterization of ASPA (Kaul et al., 1991) and the cloning of the human ASPA cDNA (Kaul et al., 1993), over 54 loss-of-function mutations have been identified (Kaul et al., 1993; Stenson et al., 2003). Only two point mutations are responsible for 98\% of the Ashkenazi Jewish cases (Glu285Ala and Tyr231X), while other (non-Ashkenazi Jewish) cases may result from a range of mutations (Michals and Matalon, 2011; Zayed, 2015). The physiological role of ASPA is to hydrolyse $N$-acetyl-L-aspartic acid (NAA), producing (e.g. in oligodendrocytes) Laspartic acid (Asp) and acetate (Ac) (see Figure 1 for more details); as expected, its deficiency leads to abnormally high central nervous system (CNS) NAA levels (>35\%) (Janson et al., 2006b), with vast amounts of NAA being excreted in urine $(N$ - 
acetylaspartic aciduria). It should be noted that urinary NAA levels are 10-100 fold higher in CD patients than age-matched healthy subjects, and this is the preferred method of CD diagnosis (Hagenfeldt, 1987).

Three forms of CD have been distinguished, differing in symptom onset and severity: (a) the "congenital form" (severest and symptoms appear within weeks of life), (b) the "infantile form" which is most common (also severe, with an onset of 2-6 months) and (c) the "juvenile form" (mildest and symptoms begin by the age of 5) (Adachi et al., 1973; Baslow and Resnik, 1997). Early symptoms of the disease include irritability, lack of head control and hypotonia, while as the disease progresses macrocephaly develops and developmental delays (particularly in motor and verbal skills) are noted, becoming increasingly apparent with age (Matalon and MichalsMatalon, 2000). At later stages some infants may come to suffer from blindness due to optic atrophy, hypotonia can evolve into spasticity, voluntary movements (including swallowing) often become impossible and seizures may occur (Gascon et al., 1990; Matalon et al., 1995). Although patients with some milder forms live beyond the age of 20, the majority of CD patients do not reach adolescence (Hoshino and Kubota, 2014).

Neuropathologically, CD is an encephalitis periaxialis diffusa (Baslow, 2000) where: (i) the failure of the white matter-seated oligodendrocytes to myelinate the local neuraxons leaves the latter intact but unsheathed (and, thus, underfunctioning), and (ii) the white matter bears a characteristic spongy degeneration due to the development of swelling (oedema) and the formation of multiple intramyelinic and extracellular fluid vacuoles (Leone et al., 1999). The vacuoles are empty, can measure up to $200 \mu \mathrm{m}$ and are primarily spotted subcortically; the deep white matter and the superficial cortex are 
less affected. Macroscopically, the brain usually appears to be heavier than expected, and bears a soft, gelatinous white matter. Microscopically, CD patients' brains are characterized by: (i) splits in the myelin lamellae and (ii) astrocytic swelling (evident both in the perikaryon and the processes) accompanied by elongated mitochondria (Adornato et al., 1972; Kumar et al., 2006; Matalon and Michals-Matalon, 1999b; Surendran et al., 2003) ${ }^{1}$.

The aim of this mini-review article is to provide an overview of the currentlyavailable knowledge on the aetiopathogenesis of CD with emphasis on the current nongenetic approaches to its treatment at both an experimental and a clinical level, by highlighting: (a) the major related hypotheses, (b) the results of the available experimental simulatory approaches, as well as (c) the relevance of the so far examined markers of CD neuropathology. In particular, the potential and the limitations of the current non-genetic neuroprotective approaches to the treatment of CD are particularly discussed in the current article, in a context that could be used as a basis for a redrafting of both future experimental and (eventually) clinical work in the field.

\section{Hypotheses on the pathogenesis of CD}

Various hypotheses have attempted to explain how the lack of ASPA activity results in the neurodegeneration and oedema seen in CD. One of them, the "Ac-lipid-myelin” hypothesis (Table 1) proposes that deficiency in NAA-derived Ac impedes myelin lipid synthesis (Baslow and Guilfoyle, 2013; Hagenfeldt et al., 1987). Although the

\footnotetext{
${ }^{1}$ for more details on the apparent oligodendrocyte number increase in the areas of dysmyelination, the phenotype of the astrocytic (Alzheimer Type 2) populations and the vacuole formation, readers are referred to the review article of Kumar et al. (2006).
} 
incorporation of acetyl moieties from NAA into myelin lipids has been observed (D’Adamo and Yatsu, 1966), it is believed to be involved in - but not being essential to - myelination, due to documentation of rare cases of CD where ASPA does not function yet myelination proceeds as normal (Janson et al., 2006a; Velinov et al., 2008). However, it should be noted that experimental evidence has suggested that ASPA is predominantly expressed in oligodendrocytes (Madhavarao et al., 2004) and that the developmental expression pattern of the ASPA gene in the postnatal rat brain closely correlates with myelination in the CNS (Kirmani et al., 2003).

A second hypothesis is the "osmotic-hydrostatic" hypothesis (Table 1), which suggests that NAA cycling between brain cells acts as a molecular water pump, removing metabolic water from neurons (Baslow et al., 1999). Once produced, NAA exists in a complex with 32 water molecules and a cation (Baslow, 2003); when depolarised, neurons in grey matter have been shown to release this NAA complex into the surrounding extracellular fluid (ECF), thus transporting water against its gradient (Sager et al., 1997). In a healthy subject, this complex rapidly diffuses into oligodendrocytes where it undergoes hydrolysis and water molecules are released (Wang et al., 2007); this free water then diffuses down its concentration gradient into the vasculature (Vajda et al., 1999). However, in CD patients, the NAA-water complex is still released upon neuronal depolarisation, but is not cleared from the ECF and instead diffuses into the vasculature (which has restricted permeability to hydrophilic molecules) (Redzic, 2011). The NAA-water complex builds up in the ECF which could lead to changes in local osmotic pressure. If a similar NAA cycle disruption occurs in white matter, the resulting osmotic pressure changes could account for the CD-related osmotic pathologies (Baslow and Guilfoyle, 2013). Although the 
depolarisation of white matter neurons has not been documented to cause NAA release into the ECF, it has been suggested that the $N$-acetylaspartylglutamic acid (NAAG) released from neurons (Figure 1) could provide a source of NAA in this case (Baslow and Guilfoyle, 2013). It is known that NAAG-peptidase within the astrocyte end feet at the nodes of Ranvier hydrolyzes NAAG to produce NAA; this is the proposed source of NAA for white matter oligodendrocytes. However, in white matter, the limited extracellular space at nodes means that a potential failure of oligodendrocyte removal of NAA and its consequent accumulation will likely have severe osmotic consequences that could explain vacuole formation and the observed splitting between myelin sheath layers (Baslow and Guilfoyle, 2013).

A very recent third hypothesis, proposed by Francis et al. (2012), is that disruption to NAA catabolism during key myelination stages in early development causes oxidative stress in myelinating oligodendrocytes resulting in dysmyelination and other CD-related pathologies. In this “oxidative stress” hypothesis (Table 1), NAA is suggested to reduce oxidative stress by preventing the coupling of fatty acid synthesis to oxidative energy metabolism through the provision of Ac. The latter can be converted to acetyl-coenzyme A (Acetyl-CoA) by acetyl-coenzyme A synthetase (ACS; Figure 1.c). Oxidative stress was shown to precede dysmyelination in nur7 mice (Francis et al., 2012) and, even more recently, Francis et al. (2014) supported their hypothesis by showing that reduction of oxidative stress by triheptanoin administration (which increases Krebs cycle intermediates) was shown to alleviate CD-related pathologies.

\section{Therapeutic approaches to CD}


Due to uncertainty concerning causative mechanisms, CD is currently incurable, with available therapies being only palliative. Non-genetic treatment is focused principally on (a) the provision of adequate hydration and nutrition by gastronomy and nasogastric feeding, (b) the use of anticonvulsants to minimise seizures (Hoshino and Kubota, 2014) and (c) the reduction of intracranial pressure using acetazolamide (Matalon and Michals-Matalon, 2000). Research into possible therapies, including lithium (Li) supplementation, Ac-supplementation, stem cell replacement and gene therapy will be discussed in this article, with a focus on non-genetic approaches.

The aim of gene therapy in CD treatment is to restore ASPA activity through ASPA gene insertion. This approach has seen a degree of success in improving the major disease symptoms; however, progress is still to be made. The use of liposome encapsulated plasmids and adeno-associated viruses as vectors to insert the ASPA gene into CD mice, tremor mice and human CD subjects has resulted in enhanced ASPA production and activity and, in some cases, reduced CNS NAA levels and improved spongiform degeneration (Ahmed et al., 2013; Klugmann et al., 2005; Leone et al., 2000; Leone et al., 2012; McPhee et al., 2005). However, it must be noted that in some cases the observed decrease in NAA and spongiform pathology is transient (Leone et al., 2012), while in others the effects are limited within a confined area surrounding the region of intracerebral injection (Leone et al., 2000; 2012). Improved motor function was noted in certain cases (Ahmed et al., 2013; Leone et al., 2012; McPhee et al., 2005), but not in all (Klugmann et al., 2005). Moreover, where motor defects were improved, they did not disappear altogether and were shown in a longitudinal study to relapse later in life (Ahmed et al., 2013). However, one pathologic marker of the 
disease, early lethality, was entirely rescued by Ahmed et al. (2013) when single intravenous injections of primate-derived adeno-associated viruses carrying the human ASPA gene were administered as late as postnatal day 20 (P20) in short-lived ASPA ${ }^{-/}$ mice; a fact that is certainly a significant step forward towards a gene-replacementmediated treatment of CD.

\section{Non-genetic therapeutic approaches to CD}

The majority of the non-genetic strategies towards CD treatment employed to date have focused on addressing either the accumulation of NAA throughout the CNS or the deficit in metabolites which results from impaired NAA hydrolysis (Figure 1). Both issues have been implicated in the pathological phenotype of $C D$, namely osmotic-mediated pathologies and dysmyelination. A synopsis of the major compounds tested as a non-genetic therapeutic approach to CD at an experimental and/or clinical level is provided in Table 2.

\section{Reduction of CNS NAA levels}

Those believing pathogenesis in CD to result principally from NAA accumulation in the CNS through mechanisms such as disrupted osmoregulation, have looked for substances that could reverse the observed CD pathology by lowering CNS NAA levels, determined through high-performance liquid chromatography (HPLC) analysis. Whilst experimental studies have identified ethanol (Baslow et al., 2000; Hirakawa et al., 1994), sodium valproate (O’Donnell et al., 2000) as well as pyrazole and a number 
of its derivatives ${ }^{2}$ (Baslow et al., 2000) to be potential candidates due to their ability to reduce NAA levels in non-diseased animal brains, when these compounds were tested in a CD animal model, no significant reductions were observed (Baslow et al., 2002) (Table 2). In this case, the CD-simulating animal model used was the CD-like tremor rat, which possesses a CD-like syndrome as a result of a naturally-occurring deletion of the ASPA gene (Kitada et al., 2000).

To date, the only substance that has persistently decreased CNS NAA levels in both animals and humans, diseased as well as non-diseased, is $\mathrm{Li}$ in both the form of $\mathrm{Li}$ chloride ( $\mathrm{LiCl})$ and Li citrate $\left(\mathrm{Li}_{3} \mathrm{C}_{6} \mathrm{H}_{5} \mathrm{O}_{7}\right)^{3}$. O’Donnell et al. (2000) have shown LiCl to reduce brain NAA levels by $9 \%$ when given to rats at a daily dosage of $170 \mathrm{mg} / \mathrm{kg}$ of body weight for 2 weeks, but it was Baslow et al. (2002) that highlighted its potential therapeutic value in CD and tested it on CD-like tremor rats (Table 2). A 13\% reduction in brain NAA levels was measured through HPLC analysis of CD-like tremor rat CNS samples following administration of $\mathrm{LiCl}$ at a dose of $300 \mathrm{mg} / \mathrm{kg}$ of body weight, daily for 4 days (Baslow et al., 2002). Interestingly, $\mathrm{Li}_{3} \mathrm{C}_{6} \mathrm{H}_{5} \mathrm{O}_{7}$ was later tested on a human CD patient (Janson et al., 2005) and achieved statisticallysignificant reduction of NAA levels in only one of the four CNS regions studied; nonetheless, NAA levels declined in all studied CNS regions in both the white and the grey matter, as measured through proton magnetic resonance spectroscopy (MRS) studies. The 18-month-old female CD patient ingested $\mathrm{Li}_{3} \mathrm{C}_{6} \mathrm{H}_{5} \mathrm{O}_{7}$ to up to $45 \mathrm{mg} / \mathrm{kg}$ of

\footnotetext{
${ }^{2}$ more specifically, the following (pyrazole-deriving) compounds which are known inhibitors of alcohol dehydrogenase: 4-pyrazolecarboxylic acid, 1- $H$-pyrazole-1-carboxamidine- $\mathrm{HCl}$, 4-methypyrazole and, pyrazole-3,5-dicarboxylic acid monohydrate.

${ }^{3}$ readers are reminded that Li compounds are used as mood stabilizing agents; their action is not yet characterized by a specific biochemical mechanism, but recent evidence suggests that Li might exert neuroprotection through a concentration of mitochondrial dysfunction (Malhi et al., 2013); a potential reason for its herein discussed effectiveness in CD.
} 
body weight per day for 4 months and her magnetic resonance imaging (MRI) scans showed that T1 changes in white matter showed greater similarity to age-matched values for healthy human subjects (compared with theoretical values for CD patients), suggesting that myelination was more normal as a result of the Li-treatment (Janson et al., 2005). Her clinical symptoms also appeared mildly improved, as the patient showed increased awareness of her surroundings, increased alertness and minor improvements in language and gross motor function (Janson et al., 2005).

A second human study on a cohort of six patients and over a time period of 60 days (Assadi et al., 2010), showed $\mathrm{Li}_{3} \mathrm{C}_{6} \mathrm{H}_{5} \mathrm{O}_{7}$ to be non-toxic at the same dosage (45 $\mathrm{mg} / \mathrm{kg}$ per day), demonstrated a statistically-significant drop in NAA levels in the basal ganglia (through proton MRS) and indicated a mildly improved myelination in the frontal white matter (from MRI T1 relaxation times). Improved alertness and social interactions were also noted, while gross motor function testing on the other hand failed to show any statistically-significant improvement (Assadi et al., 2010).

In a more recent case report (Solsona et al., 2012), $\mathrm{Li}_{3} \mathrm{C}_{6} \mathrm{H}_{5} \mathrm{O}_{7}$ was again reported to lower CNS NAA levels when given to a 3-month-old female CD patient for a year at a dosage of $45 \mathrm{mg} / \mathrm{kg}$ per day: a $20 \%$ reduction of CNS NAA levels was achieved and the substance was again well-tolerated. Moreover, alertness and visual tracking were reported to have improved, but hypotonia and spasticity remained (Solsona et al., 2012).

In all cases (Table 2), any symptomatic improvements from Li-administration were mild, but results were consistent and no adverse effects were reported following intake for up to a year. It is possible that higher dosages might be required to see greater therapeutic benefit; therefore studies on the safety of higher Li dosages in 
animals might be a beneficial prerequisite prior to any clinical attempt. The mechanism by which Li lowers CNS NAA levels is unknown ${ }^{4}$. It has been suggested to prevent NAA release from neurons or increase expulsion from the CNS by affecting blood-brain barrier (BBB) permeability (Janson et al., 2005). An alternative mechanism that could be targeted is inhibition of the NAA synthetic pathways (Baslow and Guilfoyle, 2009). The latter could either be accomplished by competitive or irreversible inhibition of aspartate $N$-acetyltransferase (AspNAT; the enzyme that synthesises NAA from Asp and Acetyl-CoA) (Figure 1.c) or by inhibiting NAAGpeptidase in order to prevent NAA synthesis from NAAG hydrolysis; the latter is further discussed below.

\section{Water removal}

Baslow and Guilfoyle (2013) have recently proposed that maintenance of a sustained increase in plasma NAA levels in CD patients, by oral NAA-administration, might be therapeutic as a means of reducing oedema and other osmotic brain pathologies seen in the disease. Baslow and Guilfoyle (2013) claim that NAA accumulation in plasma would increase plasma oncotic pressure, and since NAA is thought to be unable to pass through the $\mathrm{BBB}$, an outward water gradient from the CNS ECF to the vasculature should be established and water should exit the brain. However, studies have yet to be carried out to test this hypothesis.

Accumulation of NAA and oxidative stress

\footnotetext{
${ }^{4}$ it is worth noting that recent experimental studies have shown that Li can enhance remyelination of peripheral nerves (Makoukji et al., 2012) and influence white matter microstructure (Benedetti et al., 2013) by (probably) acting as a glucogen synthase kinase 3-beta (GSK3- $\beta$ ) inhibitor.
} 
Due to evidence that CNS NAA accumulation may be damaging through its initiation of oxidative stress (Pederzolli et al., 2007; 2009; Surendran and Bhatnagar, 2011), antioxidants have been considered as a potential treatment for CD. Lipoic acid, being known to cross the BBB and to have a high potency, was tested in its ability to reduce signs of NAA-induced oxidative stress in 14-day-old Wistar rats (Pederzolli et al., 2010): when given before acute NAA-administration (40 mg/kg of body weight, intraperitoneally, 2-days prior to NAA), all signs of oxidative stress induced by NAA were prevented. Whereas rats that received NAA alone showed increased lipid peroxidation, protein oxidation and DNA damage and decreased enzymatic and nonenzymatic defences, none of these effects were seen in rats pre-treated with lipoic acid (Pederzolli et al., 2010). These results suggest that dietary supplementation with lipoic acid could be a worthwhile approach to the treatment of $\mathrm{CD}$, but further studies must first produce evidence of symptomatic improvements in more appropriate CD animal models.

\section{Supplementation of Ac}

Other studies have focused on the "Ac-myelin-lipid” hypothesis and attempted to restore myelination through Ac-supplementation (Arun et al., 2010; Madhavarao et al., 2009; Mathew et al., 2005; Namboodiri et al., 2006; Segel et al., 2011) (Table 2). To this end, calcium Ac (CA) and glyceryl triacetate (GTA) have both been tested in their ability to deliver Ac to the CNS (Mathew et al., 2005; Namboodiri et al., 2006). Intragastric administration of equivalent amounts of CA or GTA to 21-day-old 
C57BL/6 mice showed GTA to raise CNS Ac levels much more effectively ${ }^{5}$ and to have fewer adverse effects than CA, although both were found to be reasonably safe (Mathew et al., 2005; Namboodiri et al., 2006).

A few years later, GTA was shown to be safe when orally administered in low doses to CD infant patients and in high doses to tremor rat pups, although not efficiently alleviating the CD-associated symptomatology in the human trial (Madhavarao et al., 2009). A later study (Arun et al., 2010) on the tremor rats reported increased CNS galactocerebroside ${ }^{6}$ levels, decreased spongy vacuolation and improved motor performance were noted due to high-dose administration of GTA. Moreover, once again, the treatment was well-tolerated as no toxic effects were reported (Arun et al., 2010).

Given the successful tolerance of GTA at high dosage in rats, high-dose tests (4.5 g/kg of body weight per day) were carried out on 8-month- and 1-year-old CD infants over a period of 4.5 and 6 months respectively, throughout which time neither toxicity nor motor improvements were observed (Segel et al., 2011). The latter was attributed to the late onset of treatment (Segel et al., 2011). Moreover, it should be noted that at its highest dosage so far trialled, GTA has shown limited benefit in humans (Table 2), while treatment at an earlier age could lead to improved symptoms (as was seen in tremor rats) and should be considered when designing future studies.

\section{Energetic substrates}

\footnotetext{
${ }^{5}$ it has been reported that when equimolar concentrations of GTA and CA were administered (intragastrically) to mice, CNS Ac levels were found to be higher in the GTA-fed mice; a finding suggested to reflect the ability of the hydrophobic GTA to easier penetrate cell membranes (Mathew et al., 2005; Namboodiri et al., 2006).

${ }^{6}$ galactocerebroside (or galactosylceramide) is a critical CNS myelin-associated lipid that is recognised as an oligodendrocytic marker and that is found to be specifically-reduced in the CD-like tremor rat (Wang et al., 2009).
} 
Another dietary supplement proposed for use as a non-genetic therapeutic approach to CD is the anaplerotic triglyceride "triheptanoin". Building on the earlier observation that deficient NAA hydrolysis causes acute oxidative stress by increasing the coupling of fatty acid synthesis to oxidative energy metabolism (Francis et al., 2012), Francis et al. (2014) attempted to restore oxidative integrity through provision of alternative substrates for energy production. In that study, nur7 mouse mutants in their last week of prenatal life and 2-week-old nur7 pups were fed a chow containing 35\% (as caloric composition) triheptanoin until 12-weeks of age, and analysis of the animals' brains at 12-weeks showed oxidative stress, oligodendrocyte loss and dysmyelination to have been markedly reduced, while performance on accelerating rotarod testing at this age suggested improved motor function (Francis et al., 2014) (Table 2). Notably, earliertreated mice showed the greatest improvements in all aforementioned parameters (Francis et al., 2014). However, it is not yet known how triheptanoin supplies substrates to oligodendrocytes, but triheptanoin was chosen based on its ability to produce TCA cycle intermediates whilst also providing substrates for lipogenesis.

\section{Cell therapy}

Since oligodendrocytes are an important source of CNS ASPA (Bhakoo et al., 2001), if not the most important (Baslow et al., 1999; Kirmani et al., 2002; 2003; Klugmann et al., 2003; Mhadavarao et al., 2002; 2004), repopulation of the brain of a CD patient with functional oligodendrocytes could potentially rectify much of the disease phenotype through the restoration of normal NAA metabolism. Neural stem cells have been successfully used to generate oligodendrocytes in the CD mouse model 
(Surendran et al., 2004) and these oligodendrocytes expressed a myelin-specific enzyme indicative of myelin-producing ability, but clinical outcomes of such a treatment have yet to be investigated. Although the survival rate of neural progenitor cells (NPCs) was generally high in the juvenile treated mice (Surendran et al., 2004), the migration of these cells was limited, suggesting that much progress has to be made before any results (if seen) will be widespread enough to impact upon the brain pathology of this condition. In addition to the migratory potential, the stability (Amariglio et al., 2009) and safety of transplanted and differentiated NPCs in the CD mice CNS remains to be proven, while acquiring sufficient quantities of NPCs for human transplantation is likely to be difficult (Miranda et al., 2013).

The NPCs used in the aforementioned study (Surendran et al., 2004) were also tested on their ability to act as vectors for ASPA gene therapy. After 4 weeks of transplantation, enzyme activity assays carried out on juvenile CD mice showed ASPA activity to be $16 \%$ of that measured in wild-type mice (Surendran et al., 2004). However, this activity was shown to decline in the adult mice 5 weeks after the transplantation, perhaps due to the short-term expression of the retroviral vector pLXIN in vivo (Surendran et al., 2004); one should note that the use of adenoassociated virus vectors has been suggested to increase long-term efficacy of treatment. Although further studies should be carried out in order to clarify whether ASPA activity can be sufficiently increased through this method for there to be any phenotypic improvements in CD mouse models, yet again safety, stability and migration of NPCs will still need to be considered.

Novel pharmaceutical approaches 
The anti-convulsant "topiramate" was found to decrease the velocity of head growth in two CD patients following its administration for 7 and 15 months, beginning at 6months of age in both children (Topçu et al., 2004). The mechanisms responsible for this effect are not certain, but Topçu et al. (2004) suggested that CNS water accumulation was reduced, perhaps involving carbonic anhydrase inhibition. Although the benefit of topiramate is very minor to CD patients, if the underlying mechanisms by which it acts are elucidated, more light might be shed upon the pathological basis of the disease and might be supportive of the aforementioned "osmotic-hydrostatic" hypothesis.

\section{Blocking of NAAG catabolism}

Considering the hypothesis that an important amount of NAA accumulating within the white matter of CD patients could derive from NAAG catabolism, Baslow and Guilfoyle (2009) have suggested that the use of NAAG-peptidase inhibitors or of metabotropic glutamate receptor 3 (GRM3 or mGluR3; the natural astrocytic surface target for NAAG) ${ }^{7}$ agonists and antagonists (Baslow, 2008) could slow down the dysmyelination process.

\section{Conclusion}

There are still many aspects of the pathophysiology of CD that need to be clarified. Although the intracerebral NAA accumulation and dysmyelination appear to be the major regulators of the disease's progress and phenotype, experimental evidence

\footnotetext{
${ }^{7}$ GRM3 and NAAG-peptidase are actually a complex reported to appear particularly in the white matter astrocytic cells (Baslow, 2008; Baslow and Guilfoyle, 2009; Fotuhi et al., 1994).
} 
suggests that $\mathrm{CD}$ mutations might have broader deregulating impacts on the developing CNS (Kumar et al., 2006).

It is without doubt that an efficient gene therapy for CD would be an ideal treatment approach if applied at a very early age. As such an approach still needs to be addressed through the manufacturing of long-time expression effective vectors (Surendran et al., 2006), some degree of near-term management of CD must be considered through NAA synthesis-blockage or NAA removal from the patients' CNS. To-date, the only non-genetic approach to the treatment of CD that has generated evidence towards a clinical improvement in CD patients is Li-supplementation. Interestingly, while drafting this article, Guo et al. (2015) have provided a very important study in support of the "osmotic-hydrostatic" theory (for which Lisupplementation appears as a therapeutic option). On the other hand, the supplementation of Ac through GTA has shown promise when in animal tests, but as of yet fails to achieve clinical improvements in human studies, perhaps due to late onset of the attempted treatment (Table 2).

Notably, early intervention has consistently shown to produce better results in all forms of treatment, supporting the theories that implicate disruption to early developmental myelination in the pathogenesis of CD. Targeting of oxidative stress seems likely to have a therapeutic benefit but clinical studies in these areas are still lacking. Future attempts incorporating larger cohorts, longer periods of analysis and wider dose schemes (especially in the case of studies focused on Li- and Acsupplementation) could provide more conclusive evidence of the therapeutic benefit of these approaches. Due to the rarity of the disease, the launching of a multicentre coordination initiative might be necessary in order to achieve larger cohort studies in a 
timely manner. However, even if such attempts do reach successful outcomes and produce a considerable clinical benefit, the course of the disease might not be fully obstructed until the problem is addressed at the axon-myelinating oligodendrocyte interface.

Acknowledgments: This review article is based on a part of RBR's output while on her $4^{\text {th }}$-year undergraduate (BSc in Neuroscience) research project placement at the University of Glasgow.

Conflict of interest statement: No conflicts of interest exist.

\section{References}

Adornato BT, O'Brien JS, Lampert PW, Roe TF, Neustein HB (1972) Cerebral spongy degeneration of infancy. A biochemical and ultrastructural study of affected twins. Neurology 22:202-210

Adachi M, Schneck L, Cara J, Volk BW (1973) Spongy degeneration of the central nervous system (van Bogaert and Bertrand type; Canavan’s disease). A review. Hum Pathol 4:331-347

Ahmed SS, Li H, Cao C, Sikoglu EM, Denninger AR, Su Q, Eaton S, Liso Navarro AA, Xie J, Szucs S, Zhang H, Moore C, Kirschner DA, Seyfried TN, Flotte TR, Matalon R, Gao G (2013) A single intravenous rAAV injection as late as P20 achieves efficacious and sustained CNS Gene therapy in Canavan mice. Mol Ther 21:2136-2147

Amariglio N, Hirshberg A, Scheithauer BW, Cohen Y, Loewenthal R, Trakhtenbrot L, Paz N, Koren-Michowitz M, Waldman D, Leider-Trejo L, Toren A, Constantini S, 
Rechavi G (2009) Donor-derived brain tumor following neural stem cell transplantation in an ataxia telangiectasia patient. PLoS Med 6:e1000029

Arun P, Madhavarao CN, Moffett JR, Hamilton K, Grunberg NE, Ariyannur PS, Gahl WA, Anikster Y, Mog S, Hallows WC, Denu JM, Namboodiri AM (2010) Metabolic acetate therapy improves phenotype in the tremor rat model of Canavan disease. J Inherit Metab Dis 33:195-210

Assadi M, Janson C, Wang DJ, Goldfarb O, Suri N, Bilaniuk L, Leone P (2010) Lithium citrate reduces excessive intra-cerebral $N$-acetyl aspartate in Canavan disease. Eur J Paediatr Neurol 14:354-359

Baslow MH (2003) Brain $N$-acetylaspartate as a molecular water pump and its role in the etiology of Canavan disease: a mechanistic explanation. J Mol Neurosci 21:185190

Baslow MH (2000) Canavan's spongiform leukodystrophy: a clinical anatomy of a genetic metabolic CNS disease. J Mol Neurosci 15:61-69

Baslow MH (2008) The astrocyte surface NAAG receptor and NAAG peptidase signalling complex as a therapeutic target. Drug News Perspect 21:251-257

Baslow MH, Guilfoyle DN (2009) Are astrocytes the missing link between lack of brain aspartoacylase activity and the spongiform leukodystrophy in Canavan disease? Neurochem Res 34:1523-1534

Baslow MH, Guilfoyle DN (2013) Canavan disease, a rare early-onset human spongiform leukodystrophy: insights into its genesis and possible clinical interventions. Biochimie 95:946-956

Baslow MH, Kitada K, Suckow RF, Hungund BL, Serikawa T (2002) The effects of lithium chloride and other substances on levels of brain $N$-acetyl-L-aspartic acid in Canavan disease-like rats. Neurochem Res 27:403-406

Baslow MH, Resnik TR (1997) Canavan disease. Analysis of the nature of the metabolic 
lesions responsible for development of the observed clinical symptoms. J Mol Neurosci 9:109-125

Baslow MH, Suckow RF, Hungund BL (2000) Effects of ethanol and of alcohol dehydrogenase inhibitors on the reduction of $N$-acetylaspartate levels of brain in mice in vivo: a search for substances that may have therapeutic value in the treatment of Canavan disease. J Inherit Metab Dis 23:684-692

Baslow MH, Suckow RF, Sapirstein V, Hungund BL (1999) Expression of aspartoacylase activity in cultured rat macroglial cells is limited to oligodendrocytes. J Mol Neurosci 13:47-53

Benarroch EE (2008) $N$-Acetylaspartate and $N$-acetylaspartylglutamate: neurobiology and clinical significance. Neurology 70:1353-1357

Benedetti F, Bollettini I, Barberi I, Radaelli D, Poletti S, Locatelli C, Pirovano A, Lorenzi C, Falini A, Colombo C, Smeraldi E (2013) Lithium and GSK3- $\beta$ promoter gene variants influence white matter microstructure in bipolar disorder. Neuropsychopharmacology 38:313-327

Berlinguet L, Laliberté M (1966) Metabolism of $N$-acetyl-L-aspartic acid in mice. Can J Biochem 44:783-789

Bhakoo KK, Craig TJ, Styles P (2001) Developmental and regional distribution of aspartoacylase in rat brain tissue. J Neurochem 79:211-220

Canavan MM (1931) Schilder’s encephalitis perioxalis diffusa. Neurology 15:299-308

D’Adamo AF Jr, Yatsu FM (1966) Acetate metabolism in the nervous system. N-Acetyl-Laspartic acid and the biosynthesis of brain lipids. J Neurochem 13:961-965

Fotuhi M, Standaert DG, Testa CM, Penney JB Jr, Young AB (1994) Differential expression of metabotropic glutamate receptors in the hippocampus and entorhinal cortex of the rat. Brain Res Mol Brain Res 21:283-292

Francis JS, Markov V, Leone P (2014) Dietary triheptanoin rescues oligodendrocyte loss, 
dysmyelination and motor function in the nur7 mouse model of Canavan disease. J Inherit Metab Dis 37:369-381

Francis JS, Strande L, Markov V, Leone P (2012) Aspartoacylase supports oxidative energy metabolism during myelination. J Cereb Blood Flow Metab 32:1725-1736

Gascon GG, Ozand PT, Mahdi A, Jamil A, Haider A, Brismar J, al-Nasser M (1990) Infantile CNS spongy degeneration--14 cases: clinical update. Neurology 40:1876-1882

Globus JH, Strauss I (1928) Progressive degenerative subcortical encephalopathy (Schilder's disease). Arch Neurol Psychiatry 20:1190-1228

Guo F, Bannerman P, Mills Ko E, Miers L, Xu J, Burns T, Li S, Freeman E, McDonough JA, Pleasure D (2015) Ablating $N$-acetylaspartate prevents leukodystrophy in a Canavan disease model. Ann Neurol 77:884-888

Hagenfeldt L, Bollgren I, Venizelos N (1987) N-acetylaspartic aciduria due to aspartoacylase deficiency - a new aetiology of childhood leukodystrophy. J Inherit Metab Dis $10: 135-141$

Hirakawa K, Uekusa K, Sato S, Nihira M (1994) MRI and MRS studies on acute effects of ethanol in the rat brain. Nihon Hoigaku Zasshi 48:63-74

Hoshino H, Kubota M (2014) Canavan disease: Clinical features and recent advances in research. Pediatr Int 56:477-483

Janson CG, Assadi M, Francis J, Bilaniuk L, Shera D, Leone P (2005) Lithium citrate for Canavan disease. Pediatr Neurol 33:235-243

Janson CG, Kolodny EH, Zeng BJ, Raghavan S, Pastores G, Torres P, Assadi M, McPhee S, Goldfarb O, Saslow B, Freese A, Wang DJ, Bilaniuk L, Shera D, Leone P (2006a) Mild-onset presentation of Canavan’s disease associated with novel G212A point mutation in aspartoacylase gene. Ann Neurol 59:428-431

Janson CG, McPhee SW, Francis J, Shera D, Assadi M, Freese A, Hurh P, Haselgrove J, Wang DJ, Bilaniuk L, Leone P (2006b) Natural history of Canavan disease revealed by 
proton magnetic resonance spectroscopy $\left({ }^{1} \mathrm{H}-\mathrm{MRS}\right)$ and diffusion-weighted MRI. Neuropediatrics 37:209-221

Kaul R, Casanova J, Johnson AB, Tang P, Matalon R (1991) Purification, characterization, and localization of aspartoacylase from bovine brain. J Neurochem 56:129-135

Kaul R, Gao GP, Balamurugan K, Matalon R (1993) Cloning of the human aspartoacylase cDNA and a common missense mutation in Canavan disease. Nat Genet 5:118123

Kirmani BF, Jacobowitz DM, Kallarakal AT, Namboodiri MA (2002) Aspartoacylase is restricted primarily to myelin synthesizing cells in the CNS: therapeutic implications for Canavan disease. Brain Res Mol Brain Res 107:176-182

Kirmani BF, Jacobowitz DM, Namboodiri MA (2003) Developmental increase of aspartoacylase in oligodendrocytes parallels CNS myelination. Brain Res Dev Brain Res 140:105-115

Kitada K, Akimitsu T, Shigematsu Y, Kondo A, Maihara T, Yokoi N, Kuramoto T, Sasa M, Serikawa T (2000) Accumulation of $N$-acetyl-L-aspartate in the brain of the tremor rat, a mutant exhibiting absence-like seizure and spongiform degeneration in the central nervous system. J Neurochem 74:2512-2519

Klugmann M, Leichtlein CB, Symes CW, Serikawa T, Young D, During MJ (2005) Restoration of aspartoacylase activity in CNS neurons does not ameliorate motor deficits and demyelination in a model of Canavan disease. Mol Ther 11:745-753

Klugmann M, Symes CW, Klaussner BK, Leichtlein CB, Serikawa T, Young D, During MJ (2003) Identification and distribution of aspartoacylase in the postnatal rat brain. Neuroreport 14:1837-1840

Kumar S, Mattan NS, de Vellis J (2006) Canavan disease: a white matter disorder. Ment Retard Dev Disabil Res Rev 12:157-165

Leone P, Janson CG, Bilaniuk L, Wang Z, Sorgi F, Huang L, Matalon R, Kaul R, Zeng Z, 
Freese A, McPhee SW, Mee E, During MJ (2000) Aspartoacylase gene transfer to the mammalian central nervous system with therapeutic implications for Canavan disease. Ann Neurol 48:27-38

Leone P, Janson CG, McPhee SJ, During MJ (1999) Global CNS gene transfer for a childhood neurogenetic enzyme deficiency: Canavan disease. Curr Opin Mol Ther 1:487492

Leone P, Shera D, McPhee SW, Francis JS, Kolodny EH, Bilaniuk LT, Wang DJ, Assadi M, Goldfarb O, Goldman HW, Freese A, Young D, During MJ, Samulski RJ, Janson CG (2012) Long-term follow-up after gene therapy for Canavan disease. Sci Transl Med 4:165ra163

Madhavarao CN, Arun P, Anikster Y, Mog SR, Staretz-Chacham O, Moffett JR, Grunberg NE, Gahl WA, Namboodiri AM (2009) Glyceryl triacetate for Canavan disease: a low-dose trial in infants and evaluation of a higher dose for toxicity in the tremor rat model. J Inherit Metab Dis 32:640-650

Madhavarao CN, Hammer JA, Quarles RH, Namboodiri MA (2002) A radiometric assay for aspartoacylase activity in cultured oligodendrocytes. Anal Biochem 308:314-319

Madhavarao CN, Moffett JR, Moore RA, Viola RE, Namboodiri MA, Jacobowitz DM (2004) Immunohistochemical localization of aspartoacylase in the rat central nervous system. J Comp Neurol 472:318-329

Makoukji J, Belle M, Meffre D, Stassart R, Grenier J, Shackleford G, Fledrich R, Fonte C, Branchu J, Goulard M, de Waele C, Charbonnier F, Sereda MW, Baulieu EE, Schumacher M, Bernard S, Massaad C (2012) Lithium enhances remyelination of peripheral nerves. Proc Natl Acad Sci U S A 109:3973-3978

Malhi GS, Tanious M, Das P, Coulston CM, Berk M (2013) Potential mechanisms of action of lithium in bipolar disorder. Current understanding. CNS Drugs 27:135-153

Matalon R, Michals K, Kaul R (1995) Canavan disease: from spongy degeneration to 
molecular analysis. J Pediatr 127:511-517

Matalon R, Michals K, Sebesta D, Deanching M, Gashkoff P, Casanova J (1988) Aspartoacylase deficiency and $N$-acetylaspartic aciduria in patients with Canavan disease. Am J Med Genet 29:463-471

Matalon R, Michals-Matalon K (1999a) Biochemistry and molecular biology of Canavan disease. Neurochem Res 24:507-513

Matalon R, Michals-Matalon K (1999b) Recent advances in Canavan disease. Adv Pediatr 46:493-506

Matalon RM, Michals-Matalon K (2000) Spongy degeneration of the brain, Canavan disease: biochemical and molecular findings. Front Biosci 5:D307-D311

Mathew R, Arun P, Madhavarao CN, Moffett JR, Namboodiri MA (2005) Progress toward acetate supplementation therapy for Canavan disease: glyceryl triacetate administration increases acetate, but not $N$-acetylaspartate, levels in brain. $\mathrm{J}$ Pharmacol Exp Ther 315:297-303

McPhee SW, Francis J, Janson CG, Serikawa T, Hyland K, Ong EO, Raghavan SS, Freese A, Leone P (2005) Effects of AAV-2-mediated aspartoacylase gene transfer in the tremor rat model of Canavan disease. Brain Res Mol Brain Res 135:112-121

Michals K, Matalon R (2011) Canavan disease. In: Raymond GV, Eichler F, Fatemi A, Naidu S (eds). Leukodystrophies. Mac Keith Press, London, 156-169

Miranda CO, Brites P, Mendes Sousa M, Teixeira CA (2013) Advances and pitfalls of cell therapy in metabolic leukodystrophies. Cell Transplant 22:189-204

Moffett JR, Ross B, Arun P, Madhavarao CN, Namboodiri AM (2007) N-Acetylaspartate in the CNS: from neurodiagnostics to neurobiology. Prog Neurobiol 81:89-131

Namboodiri AM, Peethambaran A, Mathew R, Sambhu PA, Hershfield J, Moffett JR, Madhavarao CN (2006) Canavan disease and the role of $N$-acetylaspartate in myelin synthesis. Mol Cell Endocrinol 252:216-223 
O’Donnell T, Rotzinger S, Nakashima TT, Hanstock CC, Ulrich M, Silverstone PH (2000) Chronic lithium and sodium valproate both decrease the concentration of myoinositol and increase the concentration of inositol monophosphates in rat brain. Brain Res 880:84-91

Pederzolli CD, Mescka CP, Scapin F, Rockenbach FJ, Sgaravatti AM, Sgarbi MB, Wyse AT, Wannmacher CM, Wajner M, Dutra-Filho CS (2007) $N$-Acetylaspartic acid promotes oxidative stress in cerebral cortex of rats. Int J Dev Neurosci 25:317324

Pederzolli CD, Rockenbach FJ, Zanin FR, Henn NT, Romagna EC, Sgaravatti AM, Wyse AT, Wannmacher CM, Wajner M, de Mattos Dutra A, Dutra-Filho CS (2009) Intracerebroventricular administration of $N$-acetylaspartic acid impairs antioxidant defenses and promotes protein oxidation in cerebral cortex of rats. Metab Brain Dis 24:283-298

Pederzolli CD, Rosa AP, de Oliveira AS, Coelho JG, Becker Dda L, Dalazen GR, Moraes TB, Dutra-Filho CS (2010) Neuroprotective role of lipoic acid against acute toxicity of $N$-acetylaspartic acid. Mol Cell Biochem 344:231-239

Redzic Z (2011) Molecular biology of the blood-brain and the blood-cerebrospinal fluid barriers: similarities and differences. Fluids Barriers CNS 8:3

Sager TN, Fink-Jensen A, Hansen AJ (1997) Transient elevation of interstitial $N$ acetylaspartate in reversible global brain ischemia. J Neurochem 68:675-682

Segel R, Anikster Y, Zevin S, Steinberg A, Gahl WA, Fisher D, Staretz-Chacham O, Zimran A, Altarescu G (2011) A safety trial of high dose glyceryl triacetate for Canavan disease. Mol Genet Metab 103:203-206

Solsona MD, Fernández LL, Boquet EM, Andrés JL (2012) Lithium citrate as treatment of Canavan disease. Clin Neuropharmacol 35:150-151

Stenson PD, Ball EV, Mort M, Phillips AD, Shiel JA, Thomas NS, Abeysinghe S, Krawczak 
M, Cooper DN (2003) Human Gene Mutation Database (HGMD): 2003 update. Hum Mutat 21:577-581

Surendran S, Bhatnagar M (2011) Upregulation of $N$-acetylaspartic acid induces oxidative stress to contribute in disease pathophysiology. Int J Neurosci 121:305-309

Surendran S, Matalon KM, Tyring SK, Matalon R (2003) Molecular basis of Canavan's disease: from human to mouse. J Child Neurol 18:604-610

Surendran S, Shihabuddin LS, Clarke J, Taksir TV, Stewart GR, Parsons G, Yang W, Tyring SK, Michals-Matalon K, Matalon R (2004) Mouse neural progenitor cells differentiate into oligodendrocytes in the brain of a knockout mouse model of Canavan disease. Brain Res Dev Brain Res 153:19-27

Topçu M, Yalnizoğlu D, Saatçi I, Haliloğlu G, Topaloğlu H, Senbil N, Onol S, Coşkun T (2004) Effect of topiramate on enlargement of head in Canavan disease: a new option for treatment of megalencephaly. Turk J Pediatr 46:67-71

Vajda Z, Berényi E, Bogner P, Repa I, Dóczi T, Sulyok E (1999) Brain adaptation to water loading in rabbits as assessed by NMR relaxometry. Pediatr Res 46:450-454

Van Bogaert L, Bertrand I (1949) Sur une idiotie familiale avec dégénérescence sponglieuse de Neuraxe (note preliminaire). Acta Neurol Belg 49:572-587

Velinov M, Zellers N, Styles J, Wisniewski K (2008) Homozygosity for mutation G212A of the gene for aspartoacylase is associated with atypical form of Canavan's disease. Clin Genet 73:288-289

Wang J, Leone P, Wu G, Francis JS, Li H, Jain MR, Serikawa T, Ledeen RW (2009) Myelin lipid abnormalities in the aspartoacylase-deficient tremor rat. Neurochem Res $34: 138-148$

Wang J, Matalon R, Bhatia G, Wu G, Li H, Liu T, Lu ZH, Ledeen RW (2007) Bimodal occurrence of aspartoacylase in myelin and cytosol of brain. J Neurochem 101:448-457 
Zayed H (2015) Canavan disease: an Arab scenario. Gene 560:9-14 
Table 1. Overview of the current three hypotheses proposed for the pathogenesis of Canavan disease (CD), their mechanism(s) and the neuroprotective approaches that could prove effective in each case.

\begin{tabular}{|c|c|}
\hline Hypothesis & Outline of the mechanism(s) and potential neuroprotectant(s) \\
\hline Ac-lipid-myelin & $\begin{array}{l}\text { - } \quad \text { in CD patients, deficiency in NAA-derived Ac results in impeded } \\
\text { myelin lipid synthesis in oligodendrocytes } \\
\text { - } \quad \text { potential therapeutic approach: CA, GTA }\end{array}$ \\
\hline osmotic-hydrostatic & $\begin{array}{l}\text { - NAA cycling between brain cells acts as a molecular water pump } \\
\text { - } \\
\text { in CD patients, the NAA-water complex builds up in the ECF, } \\
\text { leading to changes in local osmotic pressure } \\
\text { - } \\
\text { in the white matter of CD patients, the limited extracellular space } \\
\text { at nodes means that a potential failure of oligodendrocyte removal } \\
\text { of NAA (and its consequent build up) is likely having severe } \\
\text { osmotic consequences that could explain vacuole formation and } \\
\text { the observed splitting between myelin sheath layers } \\
\text { - potential therapeutic approach: ethanol, } \mathrm{LiCl}, \mathrm{Li}_{3} \mathrm{C}_{6} \mathrm{H}_{5} \mathrm{O}_{7}, \mathrm{NAA} \text {, } \\
\text { pyrazole and its derivatives, sodium valproate, topiramate }\end{array}$ \\
\hline oxidative stress & $\begin{array}{l}\text { - } \quad \text { in CD patients, disruption to NAA catabolism during key } \\
\text { myelination stages in early development causes oxidative stress in } \\
\text { myelinating oligodendrocytes, resulting in dysmyelination and } \\
\text { other CD-related pathologies } \\
\text { - } \quad \text { potential therapeutic approach: lipoic acid, triheptanoin }\end{array}$ \\
\hline
\end{tabular}

Note: the use of topiramate as a potential therapeutic approach to CD within the "osmotic-hydrostatic" hypothesis is still to be clarified / confirmed. Abbreviations used: Ac: acetate; CA: calcium acetate; ECF: extracellular fluid; GTA: glyceryl triacetate; Li: lithium; LiCl: lithium chloride; $\mathrm{Li}_{3} \mathrm{C}_{6} \mathrm{H}_{5} \mathrm{O}_{7}$ : lithium citrate; NAA: $N$-acetyl-L-aspartic acid or $N$-acetylaspartate; TCA: tricarboxylic acid. 
Table 2. Synoptic presentation of the major experimental and/or clinical studies (if any) on the efficacy of potential therapeutic compounds for Canavan disease (CD).

\begin{tabular}{|c|c|c|}
\hline Compound name & Chemical structure & Major experimental and/or clinical studies and their findings \\
\hline $\begin{array}{l}N \text {-Acetyl-L-aspartate } \\
\text { (NAA) }\end{array}$ & & $\begin{array}{l}\text { - } \text { hypothesis of use: "osmotic-hydrostatic" } \\
\text { - } \text { specific aim: increase of plasma NAA levels as a means of increasing plasma } \\
\text { oncotic pressure and generating an outward water gradient from the CNS ECF to } \\
\text { the vasculature; suggestion made by Baslow and Guilfoyle (2013) } \\
\text { - } \text { experimental study: --- } \\
\text { - } \\
\text { human trial: --- }\end{array}$ \\
\hline $\begin{array}{l}\text { Calcium acetate } \\
\text { (CA) }\end{array}$ & & $\begin{array}{l}\text { - } \text { hypothesis of use: “Ac-lipid-myelin” } \\
\text { - } \quad \text { specific aim: Ac-supplementation towards restoration of myelination } \\
\text { - } \quad \text { experimental study: Mathew et al. (2005); Namboodiri et al. (2006) } \\
\text { - } \text { major finding(s): increased CNS Ac levels in C57BL/6 mice; less efficient than } \\
\quad \text { GTA }\end{array}$ \\
\hline Ethanol & & $\begin{array}{l}\text { - } \text { hypothesis of use: "osmotic-hydrostatic” } \\
\text { - } \text { specific aim: reduction of CNS NAA levels } \\
\text { - } \quad \text { experimental study: Baslow et al. (2000) } \\
\text { - } \text { major finding(s): reduction of CNS NAA levels in healthy Swiss-Webster mice } \\
\text { - } \quad \text { experimental study: Baslow et al. (2002) } \\
\text { - } \quad \text { major finding(s): unable to reduce CNS NAA levels in CD-like tremor rats }\end{array}$ \\
\hline $\begin{array}{l}\text { Glyceryl triacetate } \\
\text { (GTA) }\end{array}$ & & $\begin{array}{l}\text { - } \text { hypothesis of use: “Ac-lipid-myelin” } \\
\text { - } \text { specific aim: Ac-supplementation towards restoration of myelination } \\
\text { - } \text { experimental study: Mathew et al. (2005); Namboodiri et al. (2006) } \\
\text { - } \quad \text { major finding(s): increased CNS Ac levels in C57BL/6 mice; more efficient than } \\
\text { CA }\end{array}$ \\
\hline
\end{tabular}


Lipoic acid

Lithium chloride (LiCl)
- experimental study: Madhavarao et al. (2009)

- major finding(s): no detectable toxicity due to high-dose GTA administration in tremor rats

- experimental study: Arun et al. (2010)

- major finding(s): increased CNS galactocerebroside levels, decreased spongy vacuolation and improved motor performance in tremor rats due to high-dose administration of GTA

- $\quad$ human trial: Madhavarao et al. (2009)

- $\quad$ subject(s): two CD patients (8- and 13-month-old)

- major finding(s): no change in CNS NAA levels, no observable pathological changes over the course of the treatment, stabilization of clinical condition without improvement

- human trial: Segel et al. (2011)

- subject(s): two CD patients (8-month- and 1-year-old)

- major finding(s): no clinical improvement, good tolerance of the high dose

- hypothesis of use: "oxidative stress”

- specific aim: reduction of NAA-induced oxidative stress; crossing of the BBB

- experimental study: Pederzolli et al. (2010)

- major finding(s): reduction of NAA-induced oxidative stress-related changes in the Wistar rat CNS through pretreatment with lipoic acid

- hypothesis of use: "osmotic-hydrostatic"

- $\quad$ specific aim: reduction of CNS NAA levels / unknown mechanism

- experimental study: O’Donnell et al. (2000)

- major finding(s): reduction of CNS NAA levels in healthy Sprague-Dawley rats

- experimental study: Baslow et al. (2002)

- major finding(s): reduction (-13\%) of CNS NAA levels in CD-like tremor rats 


\section{Lithium citrate}

$\left(\mathrm{Li}_{3} \mathrm{C}_{6} \mathrm{H}_{5} \mathrm{O}_{7}\right)$

Pyrazole and derivatives

Sodium valproate

Topiramate
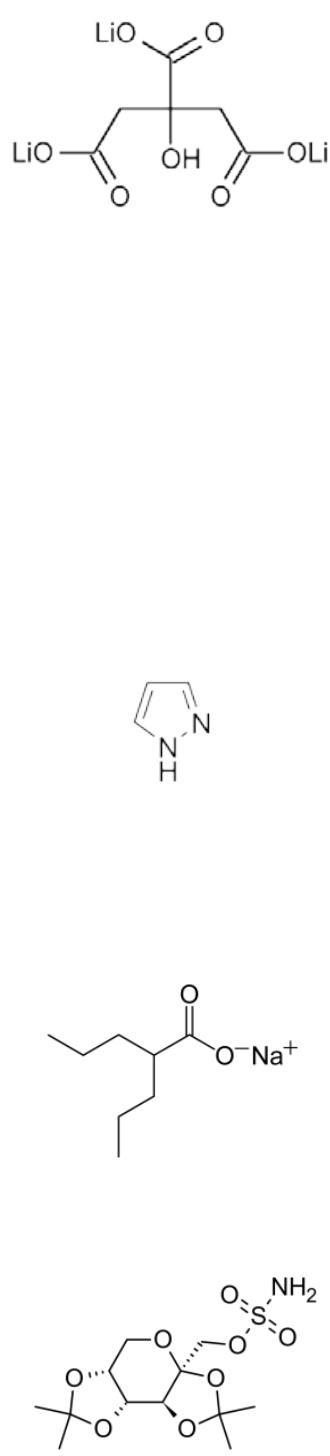

- hypothesis of use: "osmotic-hydrostatic"

- specific aim: reduction of CNS NAA levels / unknown mechanism

- human trial: Janson et al. (2005)

- subject(s): 18-month-old female CD patient

- major finding(s): reduction of CNS NAA levels, improved myelination, mild clinical improvement

- human trial: Assadi et al. (2010)

- subject(s): cohort of six CD patients (average age: 9.5 months)

- major findings: reduction of basal ganglia NAA levels, mildly improved myelination in frontal white matter, partial clinical improvement

- human trial: Solsona et al. (2012)

- subject(s): 3-month-old female CD patient

- major finding(s): reduction (-20\%) of CNS NAA levels, partial clinical improvement

- hypothesis of use: "osmotic-hydrostatic"

- specific aim: reduction of CNS NAA levels

- experimental study: Baslow et al. (2000)

- major finding(s): reduction of CNS NAA levels in healthy Swiss-Webster mice

- experimental study: Baslow et al. (2002)

- major finding(s): unable to reduce CNS NAA levels in CD-like tremor rats

- hypothesis of use: "osmotic-hydrostatic"

- specific aim: reduction of CNS NAA levels

- experimental study: O’Donnell et al. (2000)

- major finding(s): reduction of CNS NAA levels in healthy Sprague-Dawley rats

- experimental study: Baslow et al. (2002)

- major finding(s): unable to reduce CNS NAA levels in CD-like tremor rats

- hypothesis of use: "osmotic-hydrostatic" / to be clarified

- specific aim: presumably involving reduced CNS water accumulation due to carbonic anhydrase inhibition

- human trial: Topçu et al. (2004) 
- subject(s): two CD patients (13- and 21-month-old)

- major finding(s): decline in head growth velocity (as a measure of megalencephaly progression)

Triheptanoin

- hypothesis of use: "oxidative stress"

- specific aim: support of oxidative integrity, providing of ketone bodies capable of crossing of the $\mathrm{BBB}$

- experimental study: Francis et al. (2014)

- major finding(s): reduction of CNS oxidative stress, increased thalamic myelin levels and cortical oligodendrocyte survival, reduced spongiform degeneration as well as improved motor function in nur7 mice

Abbreviations used: Ac: acetate; BBB: blood-brain barrier; CNS: central nervous system; ECF: extracellular fluid. 


\section{Legend to the Figure:}

Figure 1. Overview of the metabolic pathway of $N$-acetyl-L-aspartate (NAA) within the human central nervous system. (a, b): The synthesis of NAA occurs in neuronal mitochondria (1) and, from there, NAA is transported out of the mitochondria via a putative NAA-transporter and released from neurons or transported to oligodendrocytes at the junction of the neuraxon with the inner plasma membrane of the myelin sheaths (2). The NAA reaching the oligodendrocytes is used for fatty acid / myelin lipid synthesis and energy production. On the other hand, neuronal NAA could also combine with glutamate (Glu) to produce $N$-acetylaspartylglutamate (NAAG) (1). The latter is co-released from synaptic vesicles along with several neurotransmitters and can act on the astrocytic metabotropic glutamate receptor 3 (GRM3 or mGluR3) or be hydrolyzed at the surface of astrocytes to NAA and Glu (3). In the astrocytes, Glu can combine with ammonia to produce glutamine (Gln) (4). Neurons can uptake Gln (5) and use it as a source of Glu, while both astrocytic NAA and Gln can be released to the general circulation (6). (c): Schematic overview of NAA synthesis and metabolism in neurons and oligodendrocytes. In neuronal mitochondria, pyruvate (Pyr) undergoes decarboxylation by the pyruvate dehydrogenase (PDH) complex and produces acetylcoenzyme A (Acetyl-CoA). The latter can either be introduced to the tricarboxylic acid

cycle (TCA cycle or Krebs cycle) or be combined with L-aspartic acid (Asp) to synthesize NAA via aspartate $N$-acetyltransferase (AspNAT). One NAA is transferred out of the neuronal mitochondrion, it can either be used to synthesize NAAG, to be released from the neurons or to be transferred to the oligodendrocytes. In the oligodendrocytes, NAA is hydrolyzed by aspartoacylase (ASPA; the enzyme whose 
deficiency is considered as the causing factor for Canavan disease) to produce Asp and acetate (Ac). The latter can be converted to Acetyl-CoA by acetyl-coenzyme A synthetase (ACS) which in turn can provide a substrate for the synthesis of fatty acid synthesis and myelination. Figure based on data from: Baslow and Guilfoyle (2009), Benarroch (2008), Hoshino and Kubota (2014) and Moffett et al. (2007). 
[ Figure 1]

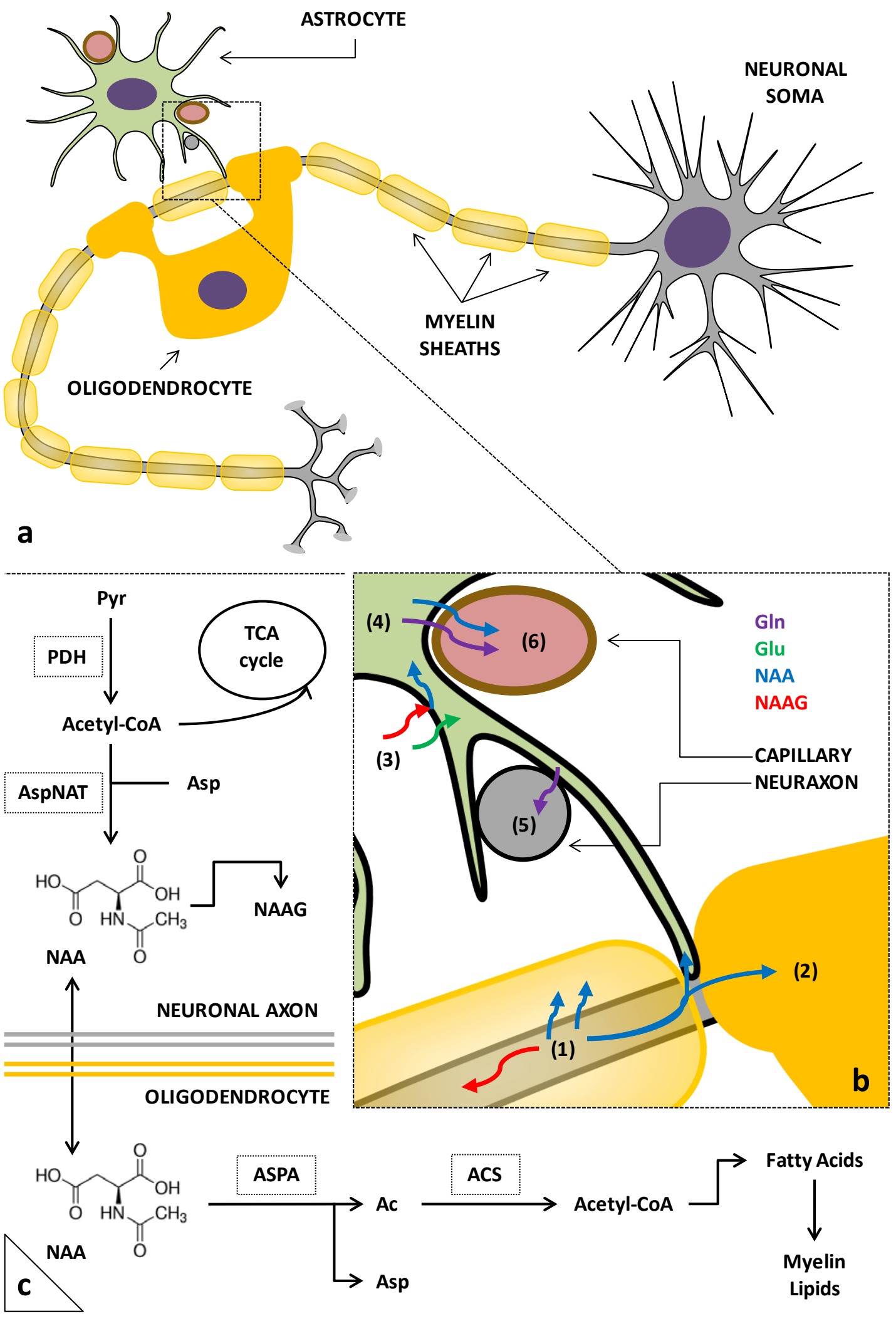

